Foro Interno. Anuario de Teoría Política

ISSN: 1578-4576

http://dx.doi.org/10.5209/FOIN.61511

\title{
Un estudio del pacto lockeano que funda el gobierno en la confianza del pueblo a la luz del caso de la prerrogativa
}

\author{
Joan Severo Chumbita ${ }^{1}$
}

Recibido: 14 de agosto de 2017 / Aprobado: 29 de diciembre de 2017

Resumen. Two Treatises of Government (TT) de John Locke (1632-1704) propone dos pactos, uno que funda el Estado y otro que funda el gobierno. La presencia de estos dos pactos supone profundas diferencias con el contractualismo hobbesiano y abre la puerta a la teoría de la resistencia lockeana. En este artículo se analizan con cierto detalle las características de ambos pactos a la luz no solo de TT sino también de otros textos de Locke a fin de precisar la especificidad y originalidad de su propuesta política. Ello supondrá discutir con la lectura de intérpretes clásicos como John Dunn y John Simmons, así como otros más contemporáneos como Lee Ward y Robert Faulkner.

Palabras claves: Locke; prerrogativa; Hobbes; soberanía; confianza.

\section{[en] A Study of the Lockean Pact that Establishes Government on the Basis of the People's Trust in Light of the Case of the Prerogative}

\begin{abstract}
John Locke's Two Treatises of Government (TT) proposes two pacts, one which establishes the State and another that establishes the government. These two pacts exhibit profound differences with the contractualism of Thomas Hobbes and open the door to the Lockean theory of resistance. In this article the characteristics of both pacts are analyzed in some detail in light, not only of $T T$ but of other texts written by Locke, with the aim of clarifying the specificity and originality of his political proposal. This will involve departing from classical interpreters such as John Dunn and John Simmons, as well as contemporary ones such as Lee Ward and Robert Faulkner.
\end{abstract}

Keywords: Locke; prerogative; Hobbes; sovereignty; trust.

Cómo citar: Joan Severo Chumbita, "Un estudio del pacto lockeano que funda el gobierno en la confianza del pueblo a la luz del caso de la prerrogativa": Foro Interno. Anuario de Teoría Política, vol. 18 (2018), pp. 75-98.

\footnotetext{
Facultad de Filosofía y Letras, Universidad de Buenos Aires. Consejo Nacional de Investigaciones Científicas y Técnicas (Argentina)

E-mail: joanchumbita@gmail.com
} 


\section{El pacto que funda el Estado}

Como es sabido, la sociedad civil surge, para John Locke², de un consentimiento libre, voluntario e individual de cada uno de sus miembros ${ }^{3}$. Para pactar es preciso ser libre ${ }^{4}$ los hombres nacen libres, bajo el imperio de la ley de la naturaleza, siempre y cuando posean racionalidad: "Así nacemos libres en tanto nacemos racionales"s. Esta condición, fundante de la legitimidad política, no se da solo en estado de naturaleza sino que se aplica también al orden civil: en todo momento los hombres se hallan bajo el imperio de la ley de la naturaleza, la cual se presenta como un mandato divino que requiere de la interpretación de la razón ${ }^{6}$. El orden civil es, por tanto, un

2 El conjunto de las citas de este artículo han sido traducidas por el autor y en todos los casos se ha mantenido la referencia al texto original. En el caso de Two Treatises of Government (TT), que será citado por párrafos, se ha empleado la edición de las obras completas (John Locke, Works of John Locke in Nine Volumes, Rivington, London, 1824, vol. IV), junto a la edición inglesa de Laslett (John Locke, Two Treatises of Government, ed. de Peter Laslett, Cambridge University Press, Cambridge, 2004). En el caso de Of Government. In the Former, the False Principles and Foundation of Sir Robert Filmer, and His Followers, Are Detected and Overthrown (TT, I) se ha consultado la traducción de Carmela Gutiérrez (John Locke, "Sobre el gobierno" en El patriarca en La polémica Filmer-Locke sobre la obediencia politica, trad. de Carmen Gutiérrez de Gambra, Instituto de Estudios Políticos, Madrid, 1966, pp. 97-277). Para Of Civil Government. The Latter, is an Essay Concerning the True Original, Extent, and End, of Civil Government (TT, II), se ha consultado la traducción de Carlos Mellizo (John Locke, Segundo Tratado sobre el Gobierno Civil. Un ensayo acerca del verdadero origen, alcance y fin del Gobierno Civil, trad. de Carlos Mellizo, Tecnos, Madrid, 1990). En menor medida, se ha consultado la traducción de Claudio Amor y Pablo Stafforini (John Locke, Ensayo sobre el gobierno civil. Un ensayo concerniente al verdadero origen, alcance y finalidad del Gobierno Civil, trad. de Claudio Amor y Pablo Stafforini, Universidad Nacional de Quilmes, Buenos Aires, 2005). De este trabajo, sin embargo, se ha tomado el recurso de introducir entre corchetes, al interior de las traducciones, los conectores y suplementos que faciliten una lectura fluida del texto, sin por ello estilizar la traducción eliminando la aridez del texto original.

3 Véase $T T$, II, $\S \S 15,22,95,97-99,102,112-113,119,121,134,171,175,186,189-193,198,212,218$; véase también John W. Yolton, "Locke on the Law of Nature": The Philosophical Review, vol. 67, n. 4 (1958), pp. 493, 496; John W. Gough, John Locke’s Political Philosophy, Oxford University Press, Oxford, 1964, pp. 31, 43; Hans Aarsleff, "The State of Nature and the Nature of Man in Locke", en John W. Yolton (ed.), John Locke: Problems and Perspectives, Cambridge University Press, Cambridge, 1969, p. 103; Jacqueline Stevens, "The Reasonableness of John Locke's Majority. Property Rights, Consent and Resistance in the Second Treatise": Political Theory, vol. 24, n. 3 (1996), pp. 437-438; John T. Scott, "The Sovereignless State and Locke's Language of Obligation": The American Political Science Review, vol. 94, n. ${ }^{\circ} 3$ (2000), p. 558; Joan S. Chumbita, "La vigencia de la ley en el estado de naturaleza lockeano: libertad, castigo, guerra justa y esclavitud": Signos filosóficos, vol. 35 (2016), pp. 82-109. Bosquejos de los desarrollos de este apartado han sido presentados previamente (véase Joan S. Chumbita, "La configuración del pueblo en la resistencia. Un abordaje contemporáneo sobre la obra de John Locke": Revista SAAP, vol. 8, n. ${ }^{\circ}$ (2014), pp. 179-182).

4 Véase $T T$, II, $\S 85$.

$5 \quad T T$, II, $\$ 61$; véase también $\S \S 4,54,62-63$; John Locke, An Essay Concerning Human Understanding. With Notes and Illustrations, and an Analysis of Mr. Locke's Doctrine of Ideas (Essay), Thomas Tegg, London, 1825, II, XXI, $\S 50,8-9,12,71$ 71; John Dunn "Consent in the Political Theory of John Locke": The Historical Journal, vol. 10, n. 2 (1967), p. 158; Raymond Polin, “John Locke's Conception of Freedom”, en John W. Yolton (ed.), John Locke: Problems and Perspectives, Cambridge University Press, Cambridge, 1969, pp. 2, 4, 6, 8, 15-16; Manfred Brocker, "Suffrage and Democracy in the Political Philosophy of John Locke": Interpretation. A Journal of Political Philosophy, vol. 37, n. ${ }^{\circ}$ 1, (2009), pp. 29-30, 33; Cecilia Abdo Ferez, "Hombría, colonialismo y castigo en John Locke", en Crimen y sí mismo. La conformación del individuo en la temprana modernidad occidental, Gorla, Buenos Aires, 2013, pp. 397-398; Chumbita, "La vigencia de la ley en el estado de naturaleza lockeano", pp. 82-109.

6 TT, II, §6, §56-58; Essay, IV, XVIII, §5-6; Thomas Hobbes, Leviatán, trad. de Carlos Mellizo, Alianza Editorial, Buenos Aires, 1999, cap. XXVI, p. 239; John Dunn, The Political Thought of John Locke. An Historical Account of the Argument of the "Two Treatises of Government", Cambridge University Press, Cambridge, 1969, p. 184. Hobbes ya advertía el problema de la interpretación de la ley de la naturaleza y, contra la idea de un derecho 
constructo que debe respetar la libertad natural, sin la cual no es posible pactar la pertenencia a la sociedad civil, es decir, dar consentimiento a la obediencia.

La exigencia de racionalidad requiere, a su vez, de una madurez de juicio que solo se alcanza en la edad adulta ${ }^{7}$. Sirviéndose de esta aclaración, Locke apela a la distinción entre el poder político y paternal para dar cuenta del pacto que funda el Estado. El pacto político tiene lugar entre adultos que voluntariamente toman decisiones libres, mientras que el poder paternal constituye una tutela momentánea que tiene por fin velar por el bien de un menor de edad que aún no ha desarrollado la capacidad racional de decidir por sí mismo ${ }^{8}$. Al ingresar a una sociedad civil, los hombres pactan renunciar voluntariamente al poder de ejecutar castigos para resolver disputas, propio del estado de naturaleza, cediéndolo al poder político centralizado que garantizará la justicia y el bien común 9 . En este sentido, el mecanismo para garantizar tanto la preservación de la libertad individual como la unidad de la sociedad civil es la aceptación como propia de la decisión mayoritaria ${ }^{10}$. Aun así, el consentimiento individual y expreso de la membrecía política no deja de ser un rasgo distintivo del pensamiento lockeano, como Alexander Carlyle se ocupa de destacar, no sin dejar de manifestar su desaprobación.

Pero yo - dice - afirmo que todos los hombres se hallan naturalmente en aquel estado [el de naturaleza] y en él permanecen hasta que, por su propio consentimiento, se hacen miembros de alguna sociedad política" [TT, II, §15]. Esto es evidentemente expresión de ese individualismo extravagante que encontramos en algunos de los estoicos y contradice la concepción racional e histórica de Aristóteles de que los hombres son por naturaleza no solo seres sociables, sino también políticos, o, como podríamos decir hoy, miembros de una sociedad política de una u otra forma ${ }^{11}$.

de resistencia del pueblo, afirmaba la necesidad de un único intérprete: el magistrado. "El robo, el asesinato, el adulterio y todas las injurias son prohibidos por las leyes de [la] naturaleza; pero a qué debemos llamar robo, a qué asesinato, a qué adulterio, a qué injuria, contra un ciudadano no es algo que viene determinado por la ley de la naturaleza, sino por la ley civil...no todo matar a un hombre es un asesinato, sino solo en la medida en que así lo determine la ley civil" (Thomas Hobbes, De Cive, trad. de Carlos Mellizo, Alianza Editorial, Madrid, 2010, p. 134; véase también pp. 266, 328, 330; Hobbes, Leviatán, XVIII, pp. 162-164; XXIII, p. 213; XXVI, p. 239). Es decir, que para Hobbes no hay lugar para apelar al derecho natural contra la interpretación del magistrado (Hobbes, De Cive, pp. 48-49).

Véase $T T$, II, $\$ 59$.

$8 \quad$ Véase $T T$, II, $\S \S 58-59,61,63,66,71$; Brocker, "Suffrage and Democracy in the Political Philosophy of John Locke", pp. 36-37; en su polémica con Robert Filmer (1588-1653), Locke afirma que el poder paternal es tanto del padre como de la madre, por lo cual nunca podría dar lugar a un derecho político hereditario por vía paterna (véase $T T$, II, §64). Al mismo tiempo, entiende que el poder del padre es muy limitado respecto a sus hijos y a su mujer, por lo que, si el poder político se basara en él, difícilmente podría justificar el absolutismo filmeriano (véase TT, II, §86; Chumbita, "La vigencia de la ley en el estado de naturaleza lockeano").

9 Véase "Obligation of Penal Laws" (OPL), en John Locke, Political Essays, ed. de Mark Goldie, Cambridge University Press, Cambridge, 2002, p. 236; Ross J. Corbett, The Lockean Commonwealth, State University of New York Press, Albany, 2009, p. 431.

10 Véase TT, II, §96; Willmoore Kendall, John Locke and the Doctrine of the Majority-Rule, University of Illinois Press, Illinois, 1965, pp. 112-119; Hanna Pitkin, "Obligation and Consent I": The American Political Science Review, vol. 59, n. 4 (1965), p. 994; Dunn "Consent in the Political Theory of John Locke", p. 171; Joan S. Chumbita, "Actores sociales y económicos en las propuestas jurídicas y normativas de John Locke": Anales del Seminario de Historia de la Filosofía, vol. 31, n. ${ }^{\circ} 1$ (2014), pp. 89-105.

11 Alexander J. Carlyle, La libertad politica. Historia de su concepto en la Edad Media y los tiempos modernos, trad. de V. Herrero, Fondo de Cultura Económica, Madrid, 1982, p. 178. 
En efecto, aun cuando en Hobbes está contemplada la posibilidad de fundación del Estado por institución a través del consentimiento individual de cada uno de sus miembros, no es la única vía legítima ${ }^{12}$. Para Locke, el pacto político surge de un consentimiento libre de hombres racionales y adultos, pero este consentimiento tiene, además, la particularidad de ser necesariamente expreso: "Nada puede convertir a ningún hombre de este modo [en un miembro del Estado], sino su ingreso efectivo en él a través de un compromiso positivo, y promesa y pacto expreso"13. Lo cual, como hemos anticipado, vale también para los hijos de ciudadanos nacidos en el seno de una sociedad civil: "Pues su hijo, cuando [se convierte en] un hombre, siendo tan completamente libre como el padre, ningún 'acto del padre puede quitar la libertad del hijo', más de lo que puede cualquiera" 14 . El consentimiento expreso es por tanto la base de la membrecía a un Estado, incluso en el caso, según Locke, común en el origen de los tiempos, de que los hijos eligieran a los padres como monarcas ${ }^{15}$.

El consentimiento tácito, en cambio, es el que permite someter a cualquier individuo a las leyes de una sociedad civil por el hecho de poseer bienes patrimoniales o recorrer el territorio bajo su jurisdicción ${ }^{16}$. En base a esta forma tácita de consentimiento, Dunn sostendrá que la obligación política no se funda en el consentimiento expreso, en cuanto el solo hecho de ser propietario o el de transitar el territorio obliga a cumplir con las leyes de ella ${ }^{17}$. Dunn entiende que la obligación se basa por tanto no en otra cosa que en la legitimidad que le da a la ley su correspondencia con la ley de la naturaleza. "El consentimiento no puede ser simplemente entendido como un hecho subjetivo, un hecho sobre la psicología del individuo. Tiene que ser entendido, ante todo, como un hecho legal sobre el orden divino de la naturaleza"18.

El problema con esta interpretación radica en que vuelve completamente superfluo el consentimiento expreso como fuente de obligación política. De adoptar esta perspectiva, la obligación política se sustentaría, hobbesianamente, en la necesidad y racionalidad del gobierno, sin importar su origen. Por lo tanto, sin pretender, por una parte, negar la importancia de la teología en la determinación del lugar fundacional de la ley de la naturaleza ${ }^{19}$, y de esta para la obligación moral de los hombres, ni, por

12 Hobbes, Leviatán, XVII, p. 157; XVIII, p. 159; XX, p. 179.

$13 T T$, II, $\S 122$, véase también $\S \S 15,62$; Stevens, "The Reasonableness of John Locke's Majority", p. 441; Lee Ward, "Locke on Executive Power and Liberal Constitutionalism": Canadian Journal of Political Science, vol. 38, n. ${ }^{\circ}$ 3, (2005), p. 726; Brocker, "Suffrage and Democracy in the Political Philosophy of John Locke", p. 30.

14 TT, II, $\S 116$; véase $\S \S 89,113-118,121-122$; Yolton, “Locke on the Law of Nature”, pp. 493, 496; Gough, John Locke's Political Philosophy, pp. 31, 43; Aarsleff, "The State of Nature and the Nature of Man in Locke", p. 103.

15 Véase TT, II, $\S \S 105-108$; Ward, "Locke on Executive Power and Liberal Constitutionalism”, p. 724.

16 Véase TT, II, §119; Pitkin, “Obligation and Consent I”, p. 995; David Wootton, "John Locke and Richard Ashcraft's Revolutionary Politics": Political Studies, vol. 40, n. ${ }^{\circ} 1$ (1992), p. 94; Stevens, "The Reasonableness of John Locke's Majority", pp. 437-438; Ross J. Corbett, "The Extraconstitutionality of Lockean Prerogative": The Review of Politics, vol. 68, n. 3 (2006), pp. 432-433.

17 Véase Dunn "Consent in the Political Theory of John Locke", pp. 162-163, 181; John Dunn, Political Obligation in Its Historical Context: Essays in Political Theory, Cambridge University Press, Cambridge, 1980, p. 32; John Dunn, “The Concept of 'Trust' in the Politics of John Locke”, en Richard Rorty, Jerome B. Schneewind y Quentin Skinner (eds.), Philosophy in History: Essay on the Historiography of Philosophy, Cambridge University Press, Cambridge, 1984, p. 280.

18 Dunn, Political Obligation in Its Historical Context, p. 32, véase también pp. 30-31.

19 Véase Joan S. Chumbita, “Teología política, libertad natural, paz relativa y secularización en el estado de naturaleza descrito por John Locke": Bajo palabra. Revista de filosofía, vol. 9, n. ${ }^{\circ} 2$ (2014), pp. 191-202; Joan $\mathrm{S}$. Chumbita "La ley de la naturaleza como mandato divino. Continuidades entre los escritos tempranos y de madurez en la obra de John Locke": Telos. Revista de Estudios Interdisciplinarios en Ciencias Sociales, vol. 17, n. ${ }^{\circ} 1$ (2015), pp. 129-150; Joan S. Chumbita, "La relación entre latitudinarismo, escepticismo, tolerancia 
otra, afirmar que el consentimiento se reduzca a un acto íntimo ("psicológico", en términos de Dunn), es preciso aclarar que la exigencia del consentimiento expreso y manifiesto no puede ser minimizada, en cuanto, en la medida en que funda la membrecía a un Estado, produce obligaciones especiales.

En primer lugar, es preciso comprender que el consentimiento expreso se sustenta en el juramento, es decir, en un hecho que no es meramente psicológico pues posee una dimensión empírica exterior, que es a su vez jurídico en cuanto crea derechos ${ }^{20}$. La importancia del juramento expreso, aun cuando no se trata de fundar la membrecía, se advierte en el documento "On Allegiance and the Revolution" $(A R)^{21}$. En efecto, a un año de la llamada Revolución Gloriosa (Glorious Revolution), Locke considera necesario que los ciudadanos, especialmente considerando a los representantes Tories, brinden una manifestación expresa de lealtad al nuevo gobierno de Guillermo III (1650-1702), en cuanto su legitimidad se basa en que salvó a Inglaterra del rey Jacobo I (1566-1625), quien estaba entregándola al papado y a Francia ${ }^{22}$. Locke sostiene que la diversidad de opiniones no supone en sí un problema para el Estado, incluso considera que puede ser saludable, en la medida en que no se extienda más allá de ciertos límites. En este caso, estos límites están dados por la asunción de la fidelidad a la religión protestante y a la independencia del reino. Ello no implica para Locke aprobar todos los actos de gobierno sino simplemente la defensa de una determinada Constitución del Estado.

Las divisiones en las opiniones y en los asuntos menores, entre aquellos que abrazan los fundamentos, no sacuden la estructura. Los gobiernos siempre han subsistido y a menudo florecido con facciones como estas, pero es imposible esperar que aquellos deben sostener cualquier constitución [sean] quienes no están dispuestos a declarar por él y como propio, el derecho del príncipe [que] ellos han de obedecer ${ }^{23}$.

A esta defensa de las supuestas bases del Estado, presuntamente en peligro bajo el reinado de Jacobo I, Locke plantea la necesidad de una manifestación pública y no del mero consentimiento tácito a través del silencio, dado que: "El silencio público es en sí mismo suficiente para levantar escrúpulos entre el pueblo y nunca faltará un casuista privado para abonarlos" 24 . De aquí también la promoción de una gran amnistía a fin de que todos se sientan "cómodos y seguros bajo el gobierno" instituido por Guillermo III ${ }^{25}$.

Locke apela, por tanto, a una doble fundamentación de la obligación: una teológica, basada en la ley de la naturaleza y en este caso asociada a la religión protestante,

y protestantismo en la obra John Locke": Contrastes. Revista Internacional de Filosofia, vol. 21, n. ${ }^{\circ} 1$ (2017), pp. 63-78.

20 Véase TT, II, §62; Dunn, Political Obligation in Its Historical Context, p. 32.

${ }^{21}$ Para la traducción de $A R$ se empleó la edición inglesa de Mark Goldie (John Locke, Political Essays, ed. de Mark Goldie, Cambridge University Press, Cambridge, 2002, pp. 306-313) y se consultó la traducción de Blanca Rodríguez López y Diego Fernández Peychaux (John Locke, Ensayo sobre la tolerancia y otros escritos sobre ética y obediencia civil, trad. de Blanca Rodríguez López y Diego A. Fernández Peychaux, Minerva, Madrid, 2011, pp. 167-176).

22 Véase $A R$, pp. 308, 311-312; TT, II, $\$ \S 62,217,221-222$; Chumbita, "La configuración del pueblo en la resistencia", pp. 177-205.

$23 \quad A R$, p. 312; véase también p. 307.

24 Ibid., p. 312.

25 Ibid., p. 309, véase pp. 308-309. 
y otra utilitaria, sustentada en la consideración de los efectos de los actos de gobierno. Sobre estas bases, rechaza la oposición entre un rey de facto y otro rey de jure:

Quienquiera que sostenga que otro tiene, por la ley y el nombramiento de Dios, un derecho $^{26}$ al trono de Inglaterra, debe ser un enemigo declarado del Rey Guillermo y del gobierno actual, y además por la más alta obligación, esta es, la del derecho divino, que no admite control ni dispensa ${ }^{27}$.

Los fracasos ${ }^{28}$ de los reinados anteriores dieron origen y derecho a la llegada del Rey Guillermo y lo llevaron al trono ${ }^{29}$.

En los últimos tiempos, me he encontrado a menudo, tanto en discursos como en la prensa, con la distinción entre un rey de facto y un rey de jure, esto es, un rey en posesión y un rey por derecho. Si el gobierno actual fue nuestra redención desde hace un año y sigue siendo nuestra [fuente de] seguridad, no nos permitamos jugar

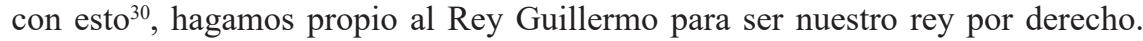
Quienquiera que rechace esto, [i]iqué hará, en efecto, sino claramente llamarlo usurpador![?] Porque [¿]qué es un usurpador sino un rey que está efectivamente en un trono al cual él no tiene derecho[?] $]^{31}$.

Como se advierte a través de este claro ejemplo, el consentimiento expreso viene a invalidar otras fuentes de legitimidad de la obligación política, como por ejemplo el derecho divino de los reyes. De aquí que sostener que el gobierno se halla obligado a observar la ley de la naturaleza no atenta contra el hecho de que lo que instituye al Estado es el consentimiento libre y voluntario de cada uno de sus miembros. De otro modo, si todos los que poseen propiedad y circulan por el territorio se hallaran en la misma obligación política que los ciudadanos miembros, no habría ninguna distinción entre el ciudadano y el extranjero. Sin embargo, Locke explícitamente señala en $T T$, II que el extranjero solo puede ser castigado en virtud de la ley de la naturaleza y no por leyes que no consintió: "[i]a través de qué derecho algún príncipe o Estado puede dar muerte o castigar a algún extranjero por algún crimen que él cometa en su país[?]. Es seguro que sus leyes, en virtud de cualquier sanción que ellos reciben de la voluntad promulgada por su legislativo, no alcanza a extraños ${ }^{32 " 33}$.

Estos pasajes permiten comprender el alcance y la importancia de la idea consentimiento expreso en la concepción lockeana. Al mismo tiempo, permiten comprender mejor la definición del poder político como potestad de dictar leyes bajo pena capital $^{34}$. Puesto que, a pesar de que no es mencionado en el parágrafo tres de $T T$, II, la definición del poder político como potestad de dictar leyes, incluso bajo pena capital, para el bien público, se aplica solo a los miembros del Estado, como se desprende del

\footnotetext{
El término es aquí nuevamente title, que en este caso debe entenderse como derecho en sentido fuerte: como título a.

27 Ibid., p. 309.

28 El término es aquí miscarriages, que también denota "abortos espontáneos", "extravíos".

29 Ibid., p. 310.

30 En el original "let us not trifle with it", siendo el significado de trifle, "tontear", "actuar con frivolidad", "despreciar".

31 Ibid., p. 311; véase John Locke, “An Essay on Toleration” (ET), en Locke, Political Essays, pp. 135-136; TT, I, $\S \S 3-5$; Chumbita, "La configuración del pueblo en la resistencia"; Chumbita, "La vigencia de la ley".

32 El término es stranger, en clara referencia a los extranjeros.

33 TT, II, §9; OPL, p. 237; Corbett, "The Extraconstitutionality of Lockean Prerogative”, pp. 432-433.

34 Véase TT, II, $\S 3 ; T T$, I, $\S \S 51,49$.
} 
parágrafo nueve que acabamos de citar. La razón de ello puede encontrarse en que el consentimiento expreso resulta fundamental para legitimar la defensa del Estado, en cuanto supone una aceptación por parte de los súbditos de este poder capital, que consiste en exigir poner en riesgo la vida en caso de necesidad ${ }^{35}$. La distinción con el extranjero no puede por tanto ser minimizada en la medida en que exige otro tipo de obligación, a pesar de que todos deban observar las leyes positivas de un Estado cuando se hallan en su territorio, así como también la ley de la naturaleza en todo momento ${ }^{36}$.

En segundo lugar, el consentimiento expreso que funda la pertenencia a la sociedad política se opone a toda forma de obediencia política bajo coacción, como es el caso de la monarquía absoluta, en la cual Locke entiende que el "súbdito" deviene en "esclavo de un príncipe absoluto" 37 , por lo que resulta "evidente que la monarquía absoluta, que es considerada por algunos hombres como el único gobierno en el mundo, es en efecto inconsistente ${ }^{38}$ con la sociedad civil" ${ }^{39}$. En este sentido, subrayando la dimensión empírica, concreta o fáctica del consentimiento expreso a la que hemos hecho referencia (y no meramente psicológica, como interpreta Dunn), Locke señala que, en caso de la instauración de un gobierno despótico, puede transcurrir mucho tiempo entre la usurpación y la resistencia.

...los habitantes de cualquier país, quienes son descendientes, y derivan un título a sus bienes inmuebles de aquellos que fueron sometidos y tuvieron un gobierno forzoso sobre ellos, contra su consentimiento libre, retienen un derecho a las posesiones de sus antecesores, aun cuando consintieron no libremente al gobierno, cuyas duras condiciones fueron impuestas por la fuerza sobre los poseedores de dicho país: pues, el primer conquistador no habiendo tenido nunca un título sobre la tierra de ese país, el pueblo ${ }^{40}$ [del] que [sus miembros] eran descendientes de, o reclamaban bajo quienes fueron forzados a someterse al yugo de un gobierno por la fuerza, tienen siempre un derecho a sacárselo de encima y de liberarse a sí mismos de la usurpación o de la tiranía que la espada les trajo sobre ellos, hasta que sus gobernantes los pongan bajo un sistema de gobierno tal que ellos voluntariamente y por elección consientan ${ }^{41}$.

Ahora bien, si tomamos como punto de partida que el Estado se funda sobre la base del consentimiento individual, podría considerarse que lo más apropiado y le-

35 Ibid. $\$ \S 139,176,192,220 ; A R$, pp. 307-308; Chumbita, "La configuración del pueblo en la resistencia".

36 En este punto, Locke también se diferencia de Hobbes, quien no sostiene esta obligación de defender voluntariamente la sociedad política con la vida en caso de necesidad (véase Hobbes, Leviatán, XXI, pp. 193-194; Dunn "Consent in the Political Theory of John Locke", p. 166; Chumbita, "La configuración del pueblo en la resistencia”).

37 TT, II, §91.

38 El término es aquí inconsistent, que también podría traducirse, menos literalmente, por "contradictorio" o "incongruente".

39 Ibid. $\S 90$; véase $§ \S 92-93,131,134-135,139-140,176,179,183-184,189,192,197$; Martin Seliger, "Locke’s Theory of Revolutionary Action": The Western Political Quarterly, vol. 16, n. ${ }^{\circ} 3$ (1963), p. 555; Óscar Godoy Arcaya, "Absolutismo, tiranía y resistencia civil en el pensamiento político de John Locke": Estudios Públicos, vol. 96 (2004), p. 279; Chumbita, "La vigencia de la ley en el estado de naturaleza lockeano".

40 El término es aquí the people, al que Locke inmediatamente se refiere a continuación en plural, refiriéndose a sus miembros.

$41 \quad$ TT, II, §192; véase TT, II, §§179, 183-184, 189, 197. 
gítimo es una concepción de la resistencia igualmente basada en derechos naturales individuales, apelando, por ejemplo, a la idea de la legítima defensa de la propiedad privada $^{42}$. Sin embargo, Locke considera inconducente e impracticable una resistencia individual: "siendo tan imposible para uno o unos pocos hombres oprimidos perturbar al gobierno, cuando la parte principal del pueblo ${ }^{43}$ no se considera concernida en ello, como es para un loco delirante o un descontento embriagado derrumbar un Estado bien establecido, el pueblo está tan poco dispuesto a seguir a uno como al otro" ${ }^{4}$. A pesar de la claridad con que Locke presenta este aspecto fundamental de la resistencia, Dunn no parece interpretarlo así, como puede apreciarse en la siguiente exégesis sobre el uso que hace Locke de la expresión "apelar a los Cielos":

Fuera de la sociedad civil, a los ojos de Locke, e incluso dentro de lo que una vez había sido una sociedad civil, donde esta última tambalea y comienza a desmoronarse, cualquiera que juzgue que sus derechos fueron violados, puede apelar solamente al Cielo. Muchos intérpretes modernos descartan esta apelación como una façon de parler, reduciéndola sin mayor consideración a su contenido pragmático secular, expulsándolo. Algunos escuchan en ella casi una broma sombría. Pero para Locke significa algo muy diferente, un recordatorio (quizás incluso un recordatorio potencialmente salvador del alma) de que Dios inclinará la balanza al final. No una implausible promesa providencial de éxito mundano para el justo, sino una garantía más allá de este mundo de que se hará verdaderamente justicia ${ }^{45}$.

Contra esta interpretación, podemos decir que si bien "cualquiera que juzgue que sus derechos fueron violados puede apelar solamente a los Cielos", ello no implica que la resistencia pueda asumir una forma individual. En efecto, la resistencia no surge cuando alguien se encuentra agraviado sino cuando una parte importante del pueblo se considera mal representada y de aquí surge la apelación a los Cielos ${ }^{46}$. En este sentido, antes que apelar a la justicia del más allá, Locke parece interesado en identificar el problema que supone la resistencia, en la medida en que no siempre conduce al triunfo de los justos, como bien destaca Seliger, coincidiendo con Dunn en este punto: "Algunas veces, entonces, el pueblo puede ser inducido ${ }^{47}$ a apoyar rebeliones injustificadas, del mismo modo que puede ser inducido a apoyar a gobernantes opresivos y conquistadores" ${ }^{\prime 4}$. En efecto, hemos visto que Locke identifica la

42 Véase ibid. \$207; Godoy Arcaya, “Absolutismo, tiranía y resistencia civil en el pensamiento político de John Locke”, p. 274; Leo Strauss, Natural Right and History, Chicago University Press, Chicago, 1992, p. 233; Diego Fernández Peychaux, La relación individuo-sociedad a través de la resistencia civil en Thomas Hobbes y John Locke, tesis doctoral inédita, Facultad de Filosofía, Universidad Complutense de Madrid, Madrid, 2012, pp. 49-50, 56.

43 En el original, the body of the people, traducimos body en su acepción como "parte principal", que es la única coherente en el contexto de la frase, ya que la idea de "masa del cuerpo" o "cuerpo del pueblo" no parecen tener sentido.

44 Ibid, §208; véase especialmente §242, §230, también §223, §240; véase Stevens, "The Reasonableness of John Locke's Majority", p. 443.

45 John Dunn, “What History Can Show: Jeremy Waldron's Reading of Locke's Christian Politics": The Review of Politics, vol. 67, n. 3 (2005), p. 448; véase también Dunn, The Political Thought of John Locke, p. 182; Godoy Arcaya, "Absolutismo, tiranía y resistencia civil en el pensamiento político de John Locke", p. 274.

46 Véase TT, II, $\S \S 192,208-209,223,225,230$; Stevens, “The Reasonableness of John Locke's Majority”, pp. 443-445.

47 El término es inveigled, que encierra tanto el sentido de seducción como de engaño.

48 Seliger, "Locke's Theory of Revolutionary Action", p. 560. 
figura del conquistador ilegítimo y este efectivamente puede triunfar por sobre los justos, a pesar de no contar con el consentimiento del pueblo ${ }^{49}$.

...muchos han confundido la fuerza de las armas por el consentimiento del pueblo, y consideran la conquista como uno de los orígenes del gobierno. Sin embargo, la conquista está tan lejos de establecer cualquier gobierno como la demolición de una casa lo está de construir una nueva en su lugar. En efecto, a menudo hace lugar para una nueva construcción de un Estado, a través de la destrucción del precedente; pero sin el consentimiento del pueblo, nunca puede erigir uno nuevo ${ }^{50}$.

Este pasaje parece sugerir que sin el consentimiento del pueblo no es posible erigir un gobierno, pero no a causa de una imposibilidad de vencer en un enfrentamiento armado, sino porque o bien el pueblo no prestaría obediencia, o bien tarde o temprano resistiría nuevamente, como hemos visto $\mathrm{ya}^{51}$. De este modo, Locke se separa de la concepción hobbesiana, según la cual el gobierno puede surgir por la institución o la conquista de un Estado ${ }^{52}$. En efecto, para Locke la conquista no puede nunca dar lugar a un gobierno político legítimo. Sin embargo, lo interesante aquí es la temporalidad que Locke propone durante la resistencia al conquistador, pues si bien la usurpación del conquistador puede perdurar por generaciones, ello no impedirá que el pueblo deje de buscar la ocasión de resistir en la búsqueda de representantes elegidos a través de una forma de gobierno consentida:

Pero los conquistados, o sus hijos, no tienen corte o árbitro en la tierra al que apelar. Por tanto, ellos pueden apelar al cielo, como hizo Jefté, y repetir su apelación hasta recuperar el derecho original de sus ancestros, que consistía en tener, un legislativo sobre ellos, que la mayoría aprobara, y libremente aceptara $^{53}$.

De este modo, se enlaza una vez más la apelación a la ley de la naturaleza, la necesidad del consentimiento expreso y una consideración fáctica y colectiva de la resistencia, la cual se sustenta en una ponderación pragmática de la relación de fuerzas y la ocasión posible para que la resistencia resulte exitosa ${ }^{54}$. De hecho, Dunn reconoce esta diferencia entre la mera sumisión y el consentimiento en relación con la conquista, a pesar de negarle centralidad en relación con la obligación política, la cual se sustenta, como hemos visto, exclusivamente en la legitimidad de la fundamentación teológica de la ley de la naturaleza ${ }^{55}$.

De este modo, queda planteada la centralidad del consentimiento expreso para la fundación del Estado así como el desplazamiento del plano individual al colectivo, el cual refleja una tensión profunda entre una dimensión normativa, basada en derechos individuales de ciudadanos-propietarios, y la dimensión colectiva y política de la resistencia efectiva, en cuanto manifiesta la decisión soberana en la situación excepcional ${ }^{56}$.

\footnotetext{
9 Chumbita, "La vigencia de la ley en el estado de naturaleza lockeano".

$50 \quad T T$, II, $\$ 175$; véase $\S 176$.

Ibid., $\S 192,176$.

Véase Hobbes, Leviatán, XVII, p. 157; XVIII, p. 159; XX, 179.

TT, II, §176; véase también $\S \S 179,183-184,189,192,197$.

Véase ibid., TT, II, §235.

Véase Dunn "Consent in the Political Theory of John Locke", pp. 175, 181.

Véase Chumbita, "La configuración del pueblo en la resistencia".
} 


\section{El pacto de confianza que funda el gobierno a la luz del ejemplo de la prerrogativa}

En este apartado se presentará el segundo pacto, que funda el gobierno, basado en la confianza que el pueblo deposita en sus representantes y que se manifiesta de modo emblemático en la prerrogativa del ejecutivo. Veremos que tal pacto constituye una de las diferencias esenciales con el contractualismo hobbesiano. De este pacto de confianza surge el hecho de que la resistencia no disuelva necesariamente al Estado sino al gobierno, razón por la cual resulta fundamental para comprender el concepto de resistencia lockeano.

En efecto, Hobbes entiende que el soberano, ya sea un magistrado o una asamblea de magistrados, no pacta en ningún momento con el conjunto de los súbditos, por lo que estos no pueden conservar una potestad de interpretar la ley de la naturaleza contra sus actos. Para Locke, en cambio, en la medida en que el pueblo delega el gobierno a través de un pacto de confianza, conserva en todo momento el poder de revocar su representación invocando la ley de la naturaleza, incluso contra el derecho positivo.

A fin de establecer la presencia de este segundo pacto de confianza que funda el gobierno, distinto del pacto que constituye el Estado a través del consentimiento expreso de cada uno de sus miembros, el modo más directo es dar cuenta de la distinción entre disolución del gobierno (government) y disolución del Estado (Commonwealth), la comunidad (community) o la sociedad política (en ocasiones, como aquí, llamada simplemente society):

El que quiera hablar de la disolución del gobierno con alguna claridad, debe distinguir, en primer lugar, entre la disolución de la sociedad y la disolución del gobierno. Lo que crea la comunidad y conduce a los hombres del inestable $e^{57}$ estado de naturaleza hacia una sociedad política es el acuerdo que cada uno tiene con el resto para incorporarse y actuar como un cuerpo, y ser por tanto un Estado distinto ${ }^{58}$.

Locke señala entonces que cuando se disuelve el Estado a través, por ejemplo, de una invasión extranjera, se disuelve también el gobierno, pues "el gobierno no puede permanecer; siendo esto tan imposible como para la estructura de una casa subsistir cuando los materiales de ella son esparcidos y dispersados por un torbellino" 59 . Sin embargo, la disolución del gobierno no supone necesariamente la disolución del Estado. El gobierno, en efecto, se auto-disuelve, lo cual significa que se desautoriza "desde adentro" mediante la realización de actos contrarios a la confianza del pueblo ${ }^{60}$. La aclaración resulta relevante, en la medida en que se ha solido identificar sin más la disolución del gobierno con el regreso al estado de naturaleza:

El estado de naturaleza es ese estado en el cual las personas pre-políticas existen; pero es también el estado en el cual cada uno de nosotros nace hoy, y en el que

\footnotetext{
57 El término es loose que refiere a lo no sujeto, aquello que le falta anclaje, por lo que podría traducirse literalmente por "suelto", "flojo".

$58 T T$, II, §211; véase Godoy Arcaya, “Absolutismo, tiranía y resistencia civil en el pensamiento político de John Locke", p. 273.

$59 \quad T T$, II, $\$ 211$.

60 Ibid., $\$ 212$.
} 
permanecemos hasta que consentimos unirnos a algún Estado; es el estado al que retornamos cuando nuestra sociedad política se disuelve (como en tiempos de guerra civil) cuando nuestros líderes políticos sobrepasan los límites de su autoridad legítima (es decir, en casos de tiranía $)^{61}$.

El derecho de resistencia dentro de la teoría de Locke está basado sobre un concepto lógicamente antitético, el estado de naturaleza o la legitimidad política. Está derivado de la noción de estado de guerra....El estado de guerra se inicia a través del uso de la fuerza. La fuerza y la violencia son los términos que aparecen en el libro como vehículos de la disrupción de la paz en el estado de naturaleza y como disolventes de la legitimidad de la sociedad política ${ }^{62}$.

A pesar de la dicotomía planteada entre sociedad civil y estado de naturaleza, la apelación al derecho de resistencia, lejos de retrotraer al estado original del hombre, produce una confrontación armada, una guerra civil, que no supone necesariamente la disolución del Estado ${ }^{63}$. En efecto, tanto en el caso de que los súbditos se encuentren bajo una monarquía absoluta, o en cualquier otro en el que personas sin autoridad ocupen cargos públicos, el gobierno se declara disuelto: "Dondequiera que haya algunas personas, quienes no tienen una autoridad tal a la que apelar por la decisión sobre cualquier diferencia entre ellos, allí esas personas están todavía en el estado de naturaleza, y así está cada príncipe absoluto con respecto a aquellos que están bajo su dominio"64. La lectura aislada de este pasaje, bien podría conducir a interpretar que la condición de los súbditos bajo el despotismo se identifica con el estado de naturaleza. Sin embargo, lo que Locke está señalando es meramente que los hombres no tienen una instancia de apelación en el orden civil para dirimir sus conflictos. Como hemos tratado en detalle en otro lugar ${ }^{65}$, y Locke aclara inmediatamente a continuación del pasaje citado, el estado de naturaleza se distingue del estado de guerra y, especialmente, de la condición de esclavitud (definida por constituir un estado de guerra) que caracteriza al despotismo: "La única y terrible diferencia para el súbdito, o mejor dicho esclavo de un príncipe absoluto, [es] que mientras que en el ordinario estado de naturaleza él tiene una libertad de juzgar sobre su derecho, y, de acuerdo con lo mejor de su poder, para mantenerlo", bajo una monarquía absoluta "se halla degradado del común estado de las criaturas racionales"66. El despotismo, como esclavitud, constituye un estado de guerra continuo y "por lo tanto expuesto a todas las desdichas e inconvenientes que un hombre puede temer de otro que, hallándose en un estado de naturaleza no restringido, está además corrompido por la adulación y armado de poder" ${ }^{\prime 67}$. Lo que ocurre durante la resistencia no es, por tanto, un retorno al estado de naturaleza sino el surgimiento de un estado de guerra en el seno de la

${ }_{61} \quad$ Alan J. Simmons, The Lockean Theory of Rights, Princeton University Press, Princeton, 1992, p. 129.

62 Dunn, The Political Thought of John Locke, p. 165; véase también Richard H. Cox, Locke on War and Peace, Oxford University Press, London, 1960, p. 66; Richard Ashcraft, "Locke's State of Nature. Historical Fact or Moral Fiction?": The American Political Science Review, vol. 62, n. 3 (1968), p. 902.

63 Véase $T T$, II, $\S \S 211,243$.

64 Ibid., $\$ 90$.

65 Joan S. Chumbita, "Las condiciones de posibilidad de la apropiación privada según John Locke. La ley y el estado de naturaleza en los escritos de madurez": Anacronismo e Irrupción, vol. 9 (2015), pp. 79-134.

${ }_{66} T T$, II, §90; Joan S. Chumbita, "Un análisis de las nociones de abundancia y esclavitud para reinterpretar el carácter universal de la teoría de la apropiación de John Locke": Las torres de Lucca. Revista Internacional de Filosofía Política, vol. 2 (2013), pp. 69-83.

67 TT, II, §91, véase también $§ \S 137,175-165$; Chumbita, "Las condiciones de posibilidad de la apropiación”. 
sociedad civil. Pues, como bien destacan Dunn y Cox en este punto, la creación de la sociedad civil no garantiza la paz eterna, el fin de todos los posibles conflictos $\operatorname{armados}^{68}$. De aquí que, como hemos visto en el apartado anterior, la conquista pueda conducir a un estado de opresión prolongado, pero no irreversible, dado que los descendientes desposeídos pueden recuperar el control del mismo Estado que, usurpado, los esclaviza ${ }^{69}$. Al mismo tiempo, resulta fundamental el análisis que hemos presentado en otros trabajos acerca de la ambigüedad de la relación entre estado de naturaleza y estado de guerra, así como entre estado de guerra y sociedad civil $^{70}$. En este sentido, es claro que no podemos entender una oposición binaria entre estado de naturaleza y sociedad civil asumiendo que el estado de guerra se hallará siempre del lado del estado de naturaleza ${ }^{71}$.

Hasta aquí, por tanto, la distinción entre disolución del Estado y disolución del gobierno. Sobre la base de esta distinción, cabe considerar la relación causal entre la traición de la confianza del pueblo y la disolución del gobierno. En este sentido, podemos decir que, en la medida en que el fin de la sociedad civil está dado por la protección de la propiedad privada, la violación de la confianza asume dos vías fundamentales, asociadas a las dos acepciones de propiedad privada (en sentido amplio, como vida, libertad y bienes, y en sentido restringido, asociada a los bienes de capital $^{72}$ ). En efecto, la representación del gobierno puede fallar tanto en base a su acepción restringida, a través de la confiscación de los bienes privados ${ }^{73}$, como en relación con la acepción amplia de propiedad, por no garantizar, fundamentalmente, el acceso a los medios de vida y la auto-preservación ${ }^{74}$. Locke va a considerar, en este sentido, tanto las obligaciones del poder legislativo como del ejecutivo, las cuales dependen, a su vez, de la Constitución como ley fundamental que establece el ordenamiento jurídico en su conjunto y la forma de gobierno que se hayan dado los miembros del Estado siguiendo la regla de la mayoría ${ }^{75}$.

Siendo el gran fin de los hombres entrando en sociedad el disfrute de sus propiedades en paz y seguridad, y siendo los grandes instrumentos y medios para ello las leyes establecidas en esa sociedad, la primera y fundamental ley positiva de todos los Estados es el establecimiento del poder legislativo, así como la primera y fundamental ley de la naturaleza, que está para gobernar incluso al legislativo

68 Véase TT, II, $\S \S 17,20,207$; Cox, Locke on War and Peace, p. 79; Dunn, The Political Thought of John Locke, p. 165.

69 Véase TT, II, $\S \S 192,175-176,179,183-184,189$, 192, 197; Chumbita, "La configuración del pueblo en la resistencia".

70 Véase Chumbita, "Las condiciones de posibilidad de la apropiación privada según Locke".

71 Véase John T. Scott, “The Sovereignless State and Locke's Language of Obligation": The American Political Science Review, vol. 94, n. ${ }^{\circ} 3$ (2000), pp. 554-555.

72 Véase Chumbita, "Actores sociales y económicos en las propuestas jurídicas y normativas de John Locke”, pp. 89-105.

73 Véase $T T$, II, $\S \S 85,131,138-140,142,168,171,222$; Brocker, "Suffrage and Democracy in the Political Philosophy of John Locke", p. 33.

74 Véase John Locke, "Some Considerations of the Lowering of Interest, and Raising the Value of Money" (SC), en Works of John Locke in Nine Volumes, Rivington, London, 1824, tomo IV, p. 71; TT, II, §§6, 168, 202-203; Godoy Arcaya, "Absolutismo, tiranía y resistencia civil en el pensamiento político de John Locke”, p. 275; Corbett, "The Extraconstitutionality of Lockean Prerogative", pp. 431-432.

75 Véase Kendall, John Locke and the Doctrine of the Majority-Rule, p. 112; Pitkin, "Obligation and Consent I", p. 994; Dunn, "Consent in the Political Theory of John Locke”, p. 171; Chumbita, "Actores sociales y conómicos en las propuestas jurídicas y normativas de John Locke”, pp. 89-105. 
mismo, es la preservación de la sociedad, y (tan lejos como fuera consistente con el bien público) de cada persona en ella ${ }^{76}$.

De este modo, el poder legislativo, como órgano supremo de los poderes constituidos del Estado, se halla sometido a la Constitución del Estado, así como a la ley de la naturaleza y los fines de la sociedad civil. Al mismo tiempo, el legislativo se encuentra supeditado en última instancia a la soberanía del pueblo: "Permanece aún en el pueblo el poder soberano de remover o alterar el legislativo, cuando ellos [los miembros del pueblo] encuentren que el legislativo ha actuado contrariamente a la confianza depositada en ellos"77. "Solo el pueblo puede determinar" ${ }^{78}$ la forma de gobierno del Estado, lo cual se realiza a través de constituir el legislativo y designar en qué manos deberá estar"79. De aquí, por ejemplo, que si bien se reconoce la necesidad de cobrar impuestos para solventar los costes del Estado, ello no implica que el gobierno disponga de una autoridad indiscriminada para aumentar los tributos sin el consentimiento del pueblo ${ }^{80}$. El gobierno posee una representación, pero supeditada a la confianza del pueblo de obrar en vistas del bien común.

En este mismo sentido, Locke sostiene que el poder ejecutivo debe velar porque el legislativo sea preservado tal como ordena la Constitución, ya que: "Cuando alguno, o más, tomaran a su cargo hacer las leyes, a quienes el pueblo no ha nombrado para hacerlo, ellos hacen leyes sin autoridad, las cuales, por tanto, el pueblo no está obligado a obedecer"81. Esto puede ocurrir por diversas posibles intromisiones del príncipe, ya sea decretando leyes, alterando la composición del legislativo arbitrariamente, no convocándolo a fin de impedir su actividad ${ }^{82}$, o bien modificando el sistema electoral de los representantes elegidos por el pueblo ${ }^{83}$. Del mismo modo, en la medida en que el rey, como miembro del ejecutivo, según la Antigua Constitución también forma parte del legislativo, en caso de que transfiera el poder confiado a su persona a un tercero, por ejemplo a un poder extranjero, ello también supondría una alteración grave del legislativo (además, obviamente, de trastocar el propio ejecutivo): "Pues el fin por el que el pueblo entró en sociedad, siendo el ser preservado [como] una sociedad entera, libre, independiente, para ser gobernada a través de sus propias leyes, esto se pierde [las mencionadas características] cuando ellos [los miembros del pueblo] son entregados al poder de otro" ${ }^{84}$. El gobierno se disuelve, a su vez, cuando se sustrae del marco provisto por la ley, a través de actos arbitrarios o la confiscación de la propiedad o la realización de atentados contra la vida y libertad

$76 \quad T T$, II, $\$ 134$; véase $\$ \S 123-128,131,135,138$.

77 Ibid., $\$ 149$.

78 El término es aquí appoint, literalmente "nombrar" o "designar". El término se repite en la misma oración, en la forma de appointing.

79 Ibid., §141; véase también §132; Scott, “The Sovereignless State and Locke’s Language of Obligation”, p. 548; Alex Tuckness, Locke and the Legislative Point of View, Princeton University Press, Princeton, 2002, pp. 128, 132-133, 140; Lee Ward, "Locke on Executive Power and Liberal Constitutionalism": Canadian Journal of Political Science, vol. 38, n. 3 (2005), pp. 728-729; Corbett, "The Extraconstitutionality of Lockean Prerogative", p. 432.

80 Véase TT, II, §140; Dunn, “Consent in the Political Theory of John Locke”, p. 170.

81 TT, II, $\$ 212$.

82 Ibid., $\S \S 155,214-215$; Godoy Arcaya, “Absolutismo, tiranía y resistencia civil en el pensamiento político de John Locke", p. 276.

83 Véase TT, II, \$216.

84 Ibid., §217, véase también §\$221-222. 
de los ciudadanos, en cuanto "cuando triunfa, produce efectos muy poco diferentes de una conquista extranjera" 85 . O bien abandonando la aplicación de las leyes, pues "es demostrativamente reducir todo a la anarquía, y por lo tanto efectivamente a disolver el gobierno" ". Ante la auto-disolución del gobierno, o la percepción del germen de una mala representación, el pueblo tiene por tanto la potestad de darse nuevas autoridades, una forma de gobierno diferente, o ambas preventivamente, es decir, antes de que sus efectos devastadores destruyan el Estado mismo:

Pero la condición de la humanidad no es tan miserable [como para] que ellos [los miembros de la humanidad] no sean capaces de aplicar este remedio hasta que sea demasiado tarde para buscar alguno. Decirle al pueblo que ellos pueden tomar precauciones para sí mismos, a través de erigir un nuevo legislativo, cuando por la opresión, artificio, o siendo entregados a un poder extranjero, su antiguo [legislativo] no está presente, es únicamente decirles que ellos pueden esperar alivio cuando es demasiado tarde y el mal está más allá de la cura. Esto es en efecto no más que ordenarles primero ser esclavos y entonces ocuparse de su libertad, y cuando sus cadenas están puestas decirles que pueden actuar como hombres. Esto es sencillamente tanto como una burla antes que un alivio y los hombres nunca pueden estar a salvo de la tiranía si no hay medios para escapar de ella hasta que están perfectamente bajo esta: y por lo tanto es que ellos tienen no solo un derecho para salir de ella sino para prevenirla ${ }^{87}$.

Ahora bien, si la confianza del pueblo supone la observancia de estas reglas constitucionales de primer orden, existe, a su vez, una confianza basada en que tanto la actividad legislativa en relación con la ley de la naturaleza, como la actividad ejecutiva con respecto a las leyes positivas (así como también las de la naturaleza), requieren de una interpretación por parte de los representantes. En efecto, la ley escrita posee silencios y oscuridades por lo que el pueblo necesariamente deposita una confianza en el ejecutivo a la hora de aplicarlas ${ }^{88}$. Esta dimensión de la confianza se manifiesta con una claridad especial en el caso de la prerrogativa con la que cuenta el poder ejecutivo para actuar, con vistas al bien común, en casos de necesidad o urgencia, incluso contra lo prescrito por la ley positiva del Estado. "Este poder de actuar a discreción, para el bien público, sin la prescripción de la ley, y algunas veces incluso contra ella, es lo que es llamado "prerrogativa" 89 . La razón de esta facultad radica en que "muchos accidentes pueden ocurrir, donde una estricta y rígida observancia de las leyes puede hacer daño" $"$. De hecho, Locke contempla la posibilidad de que, por cuestiones de necesidad, no se convoque a las sesiones del poder legislativo ${ }^{91}$. A

\footnotetext{
Ibid., §218; véase Seliger, “Locke’s Theory of Revolutionary Action”, p. 553.

TT, II, $\$ 219$.

87 Ibid., §220; véase también $\S \S 137,139,205,221$; Seliger, “Locke’s Theory of Revolutionary Action”, p. 557; Dunn, "Consent in the Political Theory of John Locke", p. 164; Dunn, The Political Thought of John Locke, pp. 178-179; Godoy Arcaya, "Absolutismo, tiranía y resistencia civil en el pensamiento político de John Locke”, pp. 272-273.

88 Véase TT, II, $§ 164$.

89 Ibid. $§ 160$, véase también $§ 158$; Seliger, “Locke’s Theory of Revolutionary Action”, pp. 566-567; Clement Fatovic, "The Political Theology of Prerogative: The Jurisprudential Miracle in Liberal Constitutional Thought": Perspectives on Politics, vol. 6, n. 3 (2008), p. 491; Brocker, "Suffrage and Democracy in the Political Philosophy of John Locke", p. 36.

$90 \quad T T$, II, §159.

91 Véase Ibid., $§ 156,159,168$.
} 
estas contingencias se añaden, a su vez, los efectos del paso del tiempo, que pueden hacer que una aplicación ciega de la ley, dados ciertos cambios de situación, altere o contraríe su espíritu original ${ }^{92}$. En efecto, "no siendo los legisladores capaces de ver el futuro, y proveer a través de las leyes por todo lo que pueda ser útil a la comunidad", las consideraciones formales y normativas no deben anteponerse a los fines de la sociedad civil ni a la observancia de la ley de la naturaleza ${ }^{93}$. La máxima a seguir por tanto se reduce a la expresión '“Salus populi, suprema lex': es, ciertamente, una regla tan justa y fundamental, que el que sinceramente la siga, no puede errar peligrosamente" 94 .

En la medida en que la prerrogativa no crea legislación sino que constituye una disposición particular basada en la confianza del pueblo, obviamente no supone un poder para establecer medidas arbitrarias contrarias al interés del pueblo, convirtiendo al ejecutivo en un poder absoluto ${ }^{95}$. En este sentido, Lee Ward entiende que la prerrogativa se opondría a la supremacía del legislativo pero no a la Constitución: "En la formulación de Locke, la prerrogativa ejecutiva es un poder extra-legal potencialmente enorme, pero no es, en el más crucial sentido, extra-constitucional" 96 . En este mismo sentido, Faulkner ya había destacado que la prerrogativa se hallaba contemplada en el modelo de la Antigua Constitución, por lo que no debía considerarse necesariamente como extra-constitucional ${ }^{97}$.

El posible equívoco de esta línea de interpretación no radica tanto en atribuir un carácter constitucional a la prerrogativa, sino en suponer que ello implicaría que Locke sostiene un positivismo jurídico, esto es, que la legitimidad de la prerrogativa descansaría en la legalidad provista por la Constitución. Contra esto hay que destacar que la legitimidad del uso de la prerrogativa no radica, para Locke, en su constitucionalidad, sino en la aceptación por parte del pueblo. Ello se advierte en que el ejercicio de la prerrogativa puede ser contrario a aspectos de la propia Constitución, y no por ello dejar de hallarse justificada en función de determinadas urgencias o

$92 \quad$ Véase ibid., §157; Corbett, "The Extraconstitutionality of Lockean Prerogative”, p. 435; Chumbita, "Actores sociales y económicos en las propuestas jurídicas y normativas de John Locke”, pp. 89-105.

93 TT, II, §159.

94 Ibid., §158, véase Marco T. Cicerón, Las leyes, trad. de C. T. Pabón de Acuña, Gredos, Madrid, 2009, III, pp. 3, 8-9; Seliger, "Locke's Theory of Revolutionary Action", pp. 558-559. Locke entiende que la presencia de este pacto de confianza entre el representante y el pueblo se manifiesta también, como veremos en detalle en el próximo apartado, a través del juramento del rey en su coronación (véase TT, II, $\S \S 151,195,198,200$ ) . Carlyle, La libertad política, p. 185). En este sentido, veremos que la primacía de la Constitución sobre el legislativo, se basa en el ejemplo de la Antigua Constitución.

95 Véase TT, II, $\S \S 163,90-94,151,166$; Ward, "Locke on Executive Power and Liberal Constitutionalism", pp. 432, 434-441, 443-444; Fatovic, "The Political Theology of Prerogative", p. 493. Del mismo modo, dado que la prerrogativa no crea leyes de validez universal, resulta análoga al modelo teológico de la ley de la fe que, a través del perdón de los pecados tiene por fin el arrepentimiento de los creyentes y la observancia de la ley de las obras, sin por ello alterarla (véase John Locke, "The Reasonableness of Christianity” ( $R$ ), en Locke, Works of John Locke in Nine Volumes, Rivington, London, 1824, tomo VI, pp. 13-15, 115; TT, II §159; Joan S. Chumbita, "La ley de la naturaleza como universal abstracto. Un estudio de los principios morales de John Locke a la luz de su crítica a la idea de sustancia”, Éndoxa. Series Filosóficas, vol. 36 (2015), pp. 99-122.

96 Ward, "Locke on Executive Power and Liberal Constitutionalism", p. 721; véase también Ruth W. Grant, John Locke's Liberalism, Chicago University Press, Chicago, London, 1987, pp. 75-76; David R. Weaver, "Leadership, Locke and the Federalist": American Journal of Political Science, vol. 41, n. 2 (1997), pp. 420-426.

97 Véase TT, II, $\S \S 163-164$. Robert Faulkner, "The First Liberal Democrat: Locke's Popular Government": Review of Politics, vol. 61, n. ${ }^{\circ} 3$ (2001), pp. 12-13, 29-33. 
necesidades ${ }^{98}$. De este modo, la concepción lockeana de la prerrogativa excede toda forma de positivismo jurídico, no porque se incluya o no el derecho de prerrogativa en una determinada Constitución, sino porque su legitimidad y aceptación tiene un sustento extra-constitucional: la aprobación del pueblo.

En este sentido, Locke discute con aquellos que sostienen que la prerrogativa se halla más allá de la decisión soberana del pueblo, invocando el derecho positivo: "Tienen una muy equivocada noción del gobierno, quienes dicen que el pueblo ha traspasado $^{99}$ la prerrogativa cuando ellos [los miembros del pueblo] no tenían ninguna parte en ella que fuese definida a través de leyes positivas"100. En efecto, Locke entiende que los miembros del pueblo poseen una potestad anterior, sobre la autoridad del representante y basada en la confianza depositada en el gobierno, que les permite rechazar el uso de la prerrogativa: "Solo declaraban que ese poder que ellos [los ciudadanos] indefinidamente habían dejado en sus manos [las del príncipe] o en las de sus antecesores para ser ejercido en su propio bien, no era lo que ellos habían pretendido cuando él lo usaba de otra manera"101. De otro modo, la prerrogativa no sería sino el modo de instaurar un gobierno por encima de las leyes, convirtiendo a los súbditos en no otra cosa que esclavos ${ }^{102}$.

\section{Diferencias con el pacto único hobbesiano}

Para concluir este artículo, se contrastará la concepción lockeana, basada en los dos pactos que hemos presentado hasta aquí, con el contractualismo de Hobbes, frente al cual Locke explícitamente construye su propuesta. Como es sabido, Hobbes desestima tanto la idea de un pacto de confianza entre el gobierno y el pueblo, como el principio mismo de soberanía popular. En efecto, Hobbes se refiere al representante del Estado como a un actor soberano en quien cada uno de los súbditos ha delegado la función de gobierno, sin que ello suponga un pacto con dichos súbditos en virtud del cual aquellos conserven un poder de interpretar la ley de la naturaleza contra la representación del soberano:

...como el derecho de representar la persona de todos es dado a quien los hombres hacen su soberano, mediante un pacto establecido entre ellos mismos, y no entre el soberano y algunos de ellos, no puede haber quebrantamiento de convenio por parte del soberano; y, en consecuencia, ninguno de sus súbditos puede librarse de estar sujeto a él, alegando algún infringimiento de contrato por su parte ${ }^{103}$.

\footnotetext{
98 Véase Scott, “The Sovereignless State and Locke's Language of Obligation”, pp. 548-549, 555; Peter Josephson, The Great Art of Government: Locke's Use of Consent, University Press of Kansas, Lawrence, 2002, pp. 231-243; Fatovic, "The Political Theology of Prerogative", pp. 439-440; Sean Mattie, "Prerogative and the Rule of Law in John Locke and the Lincoln Presidency": Review of Politics, vol. 67, n. ${ }^{\circ}$ (2005), pp. 77-111; David R. Jenkins, "The Lockean Constitution: Separation of Powers and the Limits of Prerogative": McGill Law Journal, vol. 56, n. ${ }^{\circ} 3$ (2011), pp. 445, 447.

99 El término es aquí encroached, también "invadido", "usurpado".

$100 T T$, II, $\S \S 163$, véase también $§ 164$; Faulkner, “The First Liberal Democrat: Locke’s Popular Government”, pp. 12-13, 29-33; Ward, "Locke on Executive Power and Liberal Constitutionalism”, p. 721.

101 TT, II, §163.

102 TT, II, §163-164, 90-94, 151.

103 Hobbes, Leviatán, XVIII, p. 160, véase también XVI, pp. 146-148; XVII, pp. 156-157; XVIII, p. 159; Godoy
} 
De este modo, si bien Hobbes entiende que el Estado tiene por fin salvaguardar la vida de los súbditos, el soberano no necesita buscar su aceptación, aun cuando se beneficie de hacerlo: "Pues está en su propio interés hacer leyes tales que el pueblo pueda soportarlas y observarlas sin impaciencia, y vivir con fuerza y coraje para defender a su rey y a su país contra sus vecinos poderosos" ${ }^{104}$. En efecto, el beneficio del gobierno no debe confundirse con una obligación o una confianza sobre la que deba responder: "¡Y cuánto derramamiento de sangre ha ocasionado la errónea doctrina que dice que los reyes no son superiores a la multitud, sino administradores al servicio de ella!"'105.

Se evidencia aquí la divergencia fundamental entre Locke y Hobbes respecto a la resistencia, la cual involucra posiciones opuestas respecto a la apelación a la ley de la naturaleza y al depositario de la soberanía. Pues si bien para Hobbes la protección de la propia vida y el propio cuerpo constituye un derecho y una inclinación irrenunciable ${ }^{106}$, no debe confundirse el tipo de conflictos que pueden surgir a partir de la contraposición de estos derechos, entre un individuo o un conjunto de individuos y la fuerza pública, con el concepto lockeano de resistencia ${ }^{107}$. En efecto, como hemos podido ver, para Locke la resistencia no involucra la defensa de derechos individuales sino un fenómeno político y colectivo: una apelación del pueblo a la ley de la naturaleza o a la ley positiva violentada o inaccesible. Hobbes rechaza explícitamente la resistencia en este sentido ${ }^{108}$. Para Hobbes, a través de la transferencia de derechos que realiza cada uno de los súbditos, es "el derecho de ofrecer resistencia, en virtud del cual la otra persona no podía disfrutar libremente de todos los suyos, lo que queda completamente abolido"109.

De este modo, lo que Hobbes sostiene en todo momento, aun a riesgo de inconsistencia, es la vigencia del derecho a la vida y al propio cuerpo, con un arraigo individual y explícitamente sin proyección política colectiva, como lo evidencia el famoso dilema del prisionero: "Si un súbdito es hecho prisionero en la guerra, o su persona y sus medios de vida caen bajo el control del enemigo, de modo que su vida y su libertad corporal le son concedidas bajo condición de hacerse súbdito del vencedor, tiene la libertad de aceptar esa condición""110. Aquí el Estado es contemplado meramente como instrumento para los fines del súbdito, sin suponer, a diferencia de Locke en este punto, una pertenencia política por la que valga la pena luchar arriesgando la vida ${ }^{111}$. En efecto, si algo supone la concepción lockeana de la resistencia y la lucha contra el conquistador o el usurpador es el involucramiento en disputas arriesgando la vida en función de una pertenencia como miembro de una sociedad civil. De aquí también las loas de Locke a Guillermo III, a las que ya hemos hecho referencia, en virtud de luchar por defender la religión protestante y la independencia de Inglaterra con respecto a Francia.

Arcaya, "Absolutismo, tiranía y resistencia civil en el pensamiento político de John Locke”, p. 278; Ward, "Locke on Executive Power and Liberal Constitutionalism", p. 732.

104 Thomas Hobbes, Diálogo entre un filósofo y un jurista y escritos autobiográficos, trad. de M. Á. Rodilla, Tecnos, Madrid, 1992, pp. 145-146.

105 Hobbes, De Cive, p. 41; véase también pp. 211-219; 272.

106 Véase ibid., pp. 60, 75-76, 96, 101; Hobbes, Leviatán, XXI, p. 194.

107 Véase Hobbes, Leviatán, XX, pp. 182-183; Chumbita, "La configuración del pueblo en la resistencia".

108 Véase Hobbes, Leviatán, XVIII, p. 162; XXI, pp. 189-195; XXVIII, pp. 265-266.

109 Hobbes, De Cive, pp. 68-69; véase también, pp. 49, 128-130, 132, 138-140, 149; Hobbes, Leviatán, XXIV, p. 219; XXVIII, p. 267; XXX, pp. 287-288; XXXVI, pp. 364-365.

110 Hobbes, Leviatán, XXI, p. 196, véase también XXVII, p. 259; XXIX, pp. 282-283.

111 Véase TT, II, $\S \S 176,192,220$; Hobbes, Leviatán, XXI, pp. 193-194. 
Todos, y con razón, comienzan nuestra liberación del papado y de la esclavitud a partir del arribo del Príncipe de Orange, y su completamiento ${ }^{112}$ a través de todos los que desean el bien a él [el Príncipe de Orange] y a ella [la liberación], datado a partir del establecimiento de Guillermo en el trono. Esta es la valla levantada contra el papado y Francia, dado que el nombre del Rey Jacobo, a pesar del uso hecho de [él], no puede ser sino un mustio ${ }^{113}$ pretexto para estos dos [el papado y Francia]. Si alguna vez él retorna, bajo el pretexto que fuese, los Jesuitas gobernarán y Francia será nuestro amo ${ }^{114} 115$.

Hobbes, por el contrario, a través de la solución del dilema del prisionero y la permisividad para con aquellos súbditos de "coraje" "feminoide" (feminine corage) y timidez natural (natural timorousness ${ }^{116}$ ) que no quieran pelear en la defensa del Estado, sin por ello atribuirles una deserción del servicio, da cuenta de una concepción según la cual, donde no hay garantías para la propia vida, no hay obligación política $^{117}$. De aquí también el rechazo de la apelación a un derecho de resistencia de resultados inciertos, el cual podría prolongar indefinidamente las luchas internas a partir de los desacuerdos acerca de cuál es el mejor gobierno. Hobbes, por tanto, simplemente conserva, en todo momento, el derecho de proteger la propia vida y el propio cuerpo $^{118}$.

Se manifiesta, de este modo, una diferencia profunda entre las concepciones de Hobbes y de Locke en TT, II, que puede reducirse a dos lecturas contrapuestas acerca del depositario de la soberanía: mientras que la resistencia en Locke supone la soberanía popular, Hobbes afirma en todo momento que el soberano es el magistrado, no el pueblo: “...cada ciudadano ha sometido su voluntad a quien tiene el mando supremo sobre la ciudad"119. Podemos argumentar entonces, que surge de aquí una inconsistencia ineludible al interior de esta concepción hobbesiana sobre la soberanía del

112 En el original the completing; la traducción estilizada por "cumplimiento" no parece transmitir el matiz temporal de realización, de concreción final.

113 El término es stale, que se refiere a la comida no fresca, también podría traducirse por "viejo".

114 El término empleado aquí es nuevamente master.

115 AR, pp. 307-308.

116 Si bien el término timorousness puede traducirse por "timidez", aquí parece predominar la raíz latina, referida al carácter timorato, es decir, "temeroso", por lo que mejor podría traducirse por "temerosidad natural".

117 Hobbes, Leviatán, XX, pp. 193-194; véase también p. 196; XXIX, pp. 282-283.

118 Esta fue también la posición de Locke en sus escritos tempranos, como hemos destacado en otros trabajos (Joan S. Chumbita, "La ley de la naturaleza como mandato divino", pp. 129-150). En este mismo sentido Locke dirá en "An Essay on Toleration": "Que si el magistrado, en estas opiniones o acciones, a través de leyes e imposiciones, intente restringir o compeler a los hombres en oposición a las sinceras convicciones de sus propias conciencias, deben estos hacer lo que sus conciencias requieren de ellos, tan lejos como puedan [hacerlo] sin violencia; con todo, sin embargo, están al mismo tiempo obligados a someterse silenciosamente a la pena que la ley inflige por tal desobediencia; porque a través de estos medios ellos aseguran para sí mismos sus más altos cometidos en el otro mundo y no perturban la paz de este, no atentan contra su lealtad a Dios ni al rey, sino que cumplen tanto con lo debido por ellos, como dejan a salvo el interés del magistrado y su propio bienestar" (ET, p. 143). "Yo digo, cuando cualquiera de estos distintos partidos ha crecido o está creciendo tan numeroso como para mostrarse peligroso al magistrado y parece amenazar visiblemente la paz del Estado, el magistrado puede y debe usar todas las maneras, ya sean políticas o de poder, que resulten convenientes para reducir, romper, y suprimir el partido y de este modo prevenir el daño. Porque, aunque su separación se basara en nada más que en el culto religioso y él [el magistrado] debiera usar la fuerza y la severidad como último remedio contra ellos, quienes no hicieron nada sino honrar a Dios a su manera, él, sin embargo, realmente no persiguió su religión o los castigó por ello" (ET, p. 147).

119 Hobbes, De Cive, p. 129. 
magistrado, de la cual se deriva, subsidiariamente, la contradicción entre su mandato absoluto y la posibilidad fáctica de desobediencia. En efecto, como bien destaca Hobbes, la soberanía es por definición absoluta: o bien un hombre o conjunto de hombres son los que deciden en última instancia o bien no constituyen el soberano ${ }^{120}$. De este modo, recayendo la soberanía en el representante, el correlato lógico debería ser la obediencia absoluta de los súbditos. "Pues cuando nos obligamos a obedecer antes de saber lo que se nos va a mandar, estamos universalmente atados a obedecer en todas las cosas" 121 . Sin embargo, la obediencia absoluta es fácticamente imposible, como Hobbes comprende perfectamente al señalar que "aquellas personas que van a recibir la pena capital o algún otro castigo más ligero se les pone grilletes o se las vigila estrechamente, lo cual es señal certísima de que no se estima que esas personas estaban suficientemente obligadas por sus contratos de no resistencia"122.

Para enmendar la contradicción entre soberanía del magistrado y posibilidad de desobediencia, Hobbes propone la siguiente distinción: "Una cosa es decir: Te doy derecho para que mandes lo que quieras, y otra cosa es decir: Haré cualquier cosa que me mandes. Un mandato puede ser tal, que yo prefiera morir antes que cumplirlo" 123 . Aquí la posibilidad fáctica de la desobediencia es aceptada. La cuestión es entonces si una vez aceptada la posibilidad de desobediencia del pueblo, que necesariamente debe ser evitada para que de hecho gobierne quien manda, resulta sostenible la idea de soberanía del magistrado. Hobbes insiste en que sí lo es:

Y esto, sin que se viole ese derecho absoluto que se le ha concedido al jefe supremo. Pues en ningún caso se le priva del derecho que tiene de matar a los que rehúsen obedecerle. Pero quienes deciden matar a hombres por esto, aunque se les haya concedido el derecho de hacerlo, pecarán contra las leyes de [la] naturaleza, es decir, contra Dios, si usan ese derecho de manera diferente de como es requerido por la recta razón ${ }^{124}$.

El problema de la concepción hobbesiana de la soberanía radica en la escasa entidad atribuida a la dimensión activa de la desobediencia. En efecto, una desobediencia generalizada puede llevar a que los mandatos del magistrado no se traduzcan en actos derivados de ellos por parte de los súbditos, precisamente en función de que, como Hobbes hemos visto reconoce, los súbditos pueden estar dispuestos a morir antes de obedecer determinados mandatos. Siendo así, si los mandatos del magistrado no son obedecidos por los ciudadanos, la decisión en última instancia del magistrado, es decir, su soberanía, caerá como un castillo de arena. Por lo tanto, a pesar de la distancia que propone Hobbes entre el acto de desobediencia del mandato y la vigencia de su obligatoriedad, lo cierto es que si la desobediencia se vuelve generalizada, sencillamente no habrá gobierno. En este sentido, si aceptamos la posibilidad de desobediencia, en especial la de una desobediencia generalizada, es claro que, al depender el magistrado de la obediencia del pueblo, quien decide en última instan-

120 Véase ibid., pp. 137, 145, 200.

121 Ibid., p. 234; véase también pp. 329, 335-336; Hobbes, Leviatán, XX, p. 186.

122 Hobbes, De Cive, p. 76.

123 Ibid., p. 131.

124 Ibid., p. 132, véase también p. 61; para una interpretación diversa sobre la resistencia en Hobbes, véase Fernández Peychaux, La relación individuo-sociedad a través de la resistencia civil en Thomas Hobbes y John Locke, pp. 149-170. 
cia es este último. De este modo, podemos concluir que al contrastar la concepción hobbesiana tanto con la posibilidad fáctica de la desobediencia como con la irreductibilidad propuesta de ciertos derechos individuales, la idea de la soberanía del magistrado se evidencia inconsistente. Esta es la razón por la cual Locke desestima la idea de soberanía del magistrado y propone una membrecía política que supone la obligación de luchar por ella incluso a riesgo de perder la vida. De aquí, como bien destaca Scott, que Locke reemplace la soberanía del magistrado por "el lenguaje de la obligación que ayudará a unir al Estado falto-de-soberanía"125, entendiendo por soberanía la concepción hobbesiana, es decir, no contemplando la posibilidad de la soberanía popular ${ }^{126}$.

\section{Conclusiones}

Hemos podido establecer aquí, en primer lugar, la importancia del consentimiento expreso para la fundación del Estado por parte de sus miembros. En este sentido, se ha explicitado que se trata de un hecho jurídico de particular importancia para Locke, no reductible a la legitimidad que presta la ley de la naturaleza, ni a un hecho psicológico como lo entiende Dunn. De tal pacto surge la distinción entre las obligaciones de un propietario extranjero y un ciudadano. A ello hay que añadir, como hemos visto, que el consentimiento expreso que funda la pertenencia a la sociedad civil se opone a toda forma de obediencia política bajo coacción, como es el caso de la monarquía absoluta. Se ha dado cuenta, por tanto, de la centralidad del consentimiento expreso para la fundación del Estado así como del desplazamiento del plano individual al colectivo, el cual refleja una tensión profunda entre una dimensión normativa, basada en derechos individuales de ciudadanos-propietarios, y la dimensión colectiva y política de la resistencia efectiva, en cuanto manifiesta la decisión soberana en la situación excepcional.

En segundo lugar, se dio cuenta de la importancia del pacto de confianza que, según Locke, funda el gobierno, a través del ejemplo de la prerrogativa. En efecto, existe un segundo pacto en el contractualismo lockeano que funda el gobierno, basado en la confianza que el pueblo deposita en sus representantes y que se manifiesta de modo emblemático en la prerrogativa del ejecutivo. Este pacto constituye, como hemos podido ver, una de las diferencias esenciales con el contractualismo hobbesiano. La aclaración acerca de la presencia de dos pactos resulta relevante, en la medida en que intérpretes como Simmons han solido identificar sin más la disolución del gobierno con el regreso al estado de naturaleza, lo cual, como hemos podido ver, resulta equívoco. De este segundo pacto de confianza que funda el gobierno surge el hecho de que la resistencia no disuelva necesariamente al Estado.

Al mismo tiempo, hemos discutido las lecturas de Ward y Faulkner, en cuanto al atribuir un carácter constitucional a la prerrogativa, encuentran en Locke una suerte de positivismo jurídico, al asumir que la legitimidad de la prerrogativa descansaría en la legalidad provista por la Constitución. Contra esta interpretación se ha destacado que la legitimidad del uso de la prerrogativa no radica, según Locke, en su constitucionalidad, sino en la aceptación por parte del pueblo. Ello se advierte en que

125 En el original bind together the sovereignless state.

126 Scott, “The Sovereignless State and Locke's Language of Obligation”, pp. 547, 549, 555. 
el ejercicio de la prerrogativa puede ser contrario a aspectos de la propia Constitución, y no por ello dejar de hallarse justificada en función de determinadas urgencias o necesidades.

Por último, se han destacado las profundas diferencias entre las concepciones de Hobbes y de Locke, que pueden reducirse a dos lecturas contrapuestas acerca del depositario de la soberanía: mientras que la resistencia en Locke supone la soberanía popular, Hobbes afirma en todo momento que el soberano es el magistrado, no el pueblo. En este sentido, se ha destacado que el problema de la concepción hobbesiana de la soberanía radica en la escasa entidad atribuida a la dimensión activa de la desobediencia. En efecto, una desobediencia generalizada puede llevar a que los mandatos del magistrado no se traduzcan en actos derivados de ellos por parte de los súbditos, precisamente en función de que, como Hobbes hemos visto reconoce, los súbditos pueden estar dispuestos a morir antes de obedecer determinados mandatos. Siendo así, si los mandatos del magistrado no son obedecidos por los ciudadanos, la decisión en última instancia del magistrado, es decir, su soberanía, cae como un castillo de arena.

\section{Referencias bibliográficas}

Aarsleff, Hans, "The State of Nature and the Nature of Man in Locke", en John W. Yolton (ed.), John Locke: Problems and Perspectives, Cambridge University Press, Cambridge, 1969, pp. 99-136.

Abdo Ferez, Cecilia, "Hombría, colonialismo y castigo en John Locke", en Crimen y sí mismo. La conformación del individuo en la temprana modernidad occidental, Gorla, Buenos Aires, 2013, pp. 335-451.

Ashcraft, Richard, "Locke's State of Nature. Historical Fact or Moral Fiction?": The American Political Science Review, vol. 62, n. ${ }^{\circ} 3$ (1968), pp. 898-915.

Brocker, Manfred, "Suffrage and Democracy in the Political Philosophy of John Locke": Interpretation. A Journal of Political Philosophy, vol. 37, n. ${ }^{\circ}$ (2009), pp. 29-46.

Carlyle, Alexander J., La libertad política. Historia de su concepto en la Edad Media y los tiempos modernos, trad. de V. Herrero, Fondo de Cultura Económica, Madrid, 1982.

Cicerón, Marco T., Las leyes, trad. de C. T. Pabón de Acuña, Gredos, Madrid, 2009.

Corbett, Ross J., The Lockean Commonwealth, State University of New York Press, Albany, 2009.

Corbett, Ross J., "The Extraconstitutionality of Lockean Prerogative": The Review of Politics, vol. 68, n. ${ }^{\circ} 3$ (2006), pp. 428-448.

Cox, Richard, Locke on War and Peace, Oxford University Press, London, 1960.

Chumbita, Joan Severo, "Un análisis de las nociones de abundancia y esclavitud para reinterpretar el carácter universal de la teoría de la apropiación de John Locke": Las torres de Lucca. Revista Internacional de Filosofía Política, vol. 2 (2013), pp. 69-83.

—, "La configuración del pueblo en la resistencia. Un abordaje contemporáneo sobre la obra de John Locke": Revista SAAP, vol. 8, n. 1 (2014), pp. 177-205.

—, "Actores sociales y económicos en las propuestas jurídicas y normativas de John Locke": Anales del Seminario de Historia de la Filosofía, vol. 31, n. 1 (2014), pp. 89-105.

—, "Teología política, libertad natural, paz relativa y secularización en el estado de naturaleza descrito por John Locke": Bajo palabra. Revista de filosofía, vol. 9, n. 2 (2014), pp. 191-202. 
—, "La ley de la naturaleza como mandato divino. Continuidades entre los escritos tempranos y de madurez en la obra de John Locke": Telos. Revista de Estudios Interdisciplinarios en Ciencias Sociales, vol. 17, n. ${ }^{\circ} 1$ (2015), pp. 129-150.

_- "Las condiciones de posibilidad de la apropiación privada según John Locke. La ley y el estado de naturaleza en los escritos de madurez": Anacronismo e Irrupción, vol. 9 (2015), pp. 79-134.

—, "La ley de la naturaleza como universal abstracto. Un estudio de los principios morales de John Locke a la luz de su crítica a la idea de sustancia": Éndoxa. Series Filosóficas, vol. 36 (2015), pp. 99-122.

_- "La vigencia de la ley en el estado de naturaleza lockeano: libertad, castigo, guerra justa y esclavitud": Signos filosóficos, vol. 35 (2016), pp. 82-109.

—, "La relación entre latitudinarismo, escepticismo, tolerancia y protestantismo en la obra John Locke": Contrastes. Revista Internacional de Filosofía, vol. 21, n. ${ }^{\circ} 1$ (2017), pp. 63-78.

Dunn, John, "Consent in the Political Theory of John Locke": The Historical Journal, vol. 10, n. ${ }^{\circ} 2$ (1967), pp. 153-182.

-, The Political Thought of John Locke. An Historical Account of the Argument of the "Two Treatises of Government”, Cambridge University Press, Cambridge, 1969.

-, Political Obligation in Its Historical Context: Essays in Political Theory, Cambridge University Press, Cambridge, 1980.

—, "The Concept of "Trust' in the Politics of John Locke", en Richard Rorty, Jerome B. Schneewind y Quentin Skinner (eds.), Philosophy in History: Essays on the Historiography of Philosophy, Cambridge University Press, Cambridge, 1984.

-, "What History Can Show: Jeremy Waldron's Reading of Locke's Christian Politics": The Review of Politics, vol. 67, n. 3 (2005), pp. 433-450.

Fatovic, Clement, "The Political Theology of Prerogative: The Jurisprudential Miracle in Liberal Constitutional Thought": Perspectives on Politics, vol. 6, n. ${ }^{\circ} 3$ (2008), pp. $487-$ 501.

Faulkner, Robert, "The First Liberal Democrat: Locke's Popular Government": Review of Politics, vol. 61, n. ${ }^{\circ} 1$ (2001), pp. 5-40.

Fernández Peychaux, Diego, La relación individuo-sociedad a través de la resistencia civil en Thomas Hobbes y John Locke, tesis doctoral inédita, Facultad de Filosofía, Universidad Complutense de Madrid, Madrid, 2012.

Grant, Ruth W., John Locke's Liberalism, Chicago University Press, Chicago, London, 1987.

Godoy Arcaya, Óscar, “Absolutismo, tiranía y resistencia civil en el pensamiento político de John Locke”: Estudios Públicos, vol. 96 (2004), pp. 247-280.

Gough, John W., John Locke's Political Philosophy, Oxford University Press, Oxford, 1964. Hobbes, Thomas, Diálogo entre un filósofo y un jurista y escritos autobiográficos, trad. de M. Á. Rodilla, Tecnos, Madrid, 1992.

—, Leviatán, trad. de Carlos Mellizo, Alianza Editorial, Madrid, 1999.

—, De Cive, trad. de Carlos Mellizo, Alianza Editorial, Madrid, 2010.

Jenkins, David R., "The Lockean Constitution: Separation of Powers and the Limits of Prerogative": McGill Law Journal, vol. 56, n. 3 (2011), pp. 544-586.

Josephson, Peter, The Great Art of Government: Locke's Use of Consent, University Press of Kansas, Lawrence, 2002.

Kendall, Willmoore, John Locke and the Doctrine of the Majority-Rule, University of Illinois Press, Illinois, 1965. 
Locke, John, Two Treatises of Government, en Works of John Locke in Nine Volumes, Rivington, London, 1824, tomo IV.

- "Some Considerations of the Lowering of Interest, and Raising the Value of Money", en Works of John Locke in Nine Volumes, Rivington, London, 1824, tomo IV.

- , "The Reasonableness of Christianity", en Works of John Locke in Nine Volumes, Rivington, London, 1824, tomo VI.

-, An Essay Concerning Human Understanding. With Notes and Illustrations, and an Analysis of Mr. Locke's Doctrine of Ideas, Thomas Tegg, London, 1825.

—, "Sobre el gobierno", en El patriarca en La polémica Filmer-Locke sobre la obediencia política, trad. de Carmen Gutiérrez de Gambra, Instituto de Estudios Políticos, Madrid, 1966, pp. 97-277.

-, Segundo Tratado sobre el Gobierno Civil. Un ensayo acerca del verdadero origen, alcance y fin del Gobierno Civil, trad. de Carlos Mellizo, Tecnos, Madrid, 1990.

—, "An Essay on Toleration", en Political Essays, ed. de Mark Goldie, Cambridge University Press, Cambridge, 2002, pp. 134-159.

—, "Obligation of Penal Laws", en Political Essays, ed. de Mark Goldie, Cambridge University Press, Cambridge, 2002, pp. 235-237.

- , "On Allegiance and the Revolution", en Political Essays, ed. de Mark Goldie, Cambridge University Press, Cambridge, 2002, pp. 306-313.

-, Two Treatises of Government, ed. de Peter Laslett, Cambridge University Press, Cambridge, 2004.

-, Ensayo sobre el gobierno civil. Un ensayo concerniente al verdadero origen, alcance y finalidad del Gobierno Civil, trad. de Claudio Amor y Pablo Stafforini, Universidad Nacional de Quilmes, Buenos Aires, 2005.

-, Ensayo sobre la tolerancia y otros escritos sobre ética y obediencia civil, trad. de Blanca Rodríguez López y Diego A. Fernández Peychaux, Minerva, Madrid, 2011.

Mattie, Sean, "Prerogative and the Rule of Law in John Locke and the Lincoln Presidency": Review of Politics, vol. 67, n. ${ }^{\circ} 1$ (2005), pp. 77-111.

Pitkin, Hanna, "Obligation and Consent I": The American Political Science Review, vol. 59, n. ${ }^{\circ} 4$ (1965), pp. 940-999.

Polin, Raymond, “John Locke's Conception of Freedom”, en John W. Yolton (ed.), John Locke: Problems and Perspectives, Cambridge University Press, Cambridge, 1969, pp. 1-18.

Scott, John T., "The Sovereignless State and Locke's Language of Obligation": The American Political Science Review, vol. 94, n. 3 (2000), pp. 547-561.

Seliger, Martin, “Locke's Theory of Revolutionary Action”: The Western Political Quarterly, vol. 16, n. $^{\circ} 3$ (1963), pp. 548-568.

Stevens, Jacqueline, “The Reasonableness of John Locke's Majority. Property Rights, Consent and Resistance in the Second Treatise": Political Theory, vol. 24, n. ${ }^{\circ} 3$ (1996), pp. 423-463.

Simmons, Alan J., The Lockean Theory of Rights, Princeton University Press, Princeton, 1992.

Strauss, Leo, Natural Right and History, Chicago University Press, Chicago, 1992.

Tuckness, Alex, Locke and the Legislative Point of View, Princeton University Press, Princeton, 2002.

Ward, Lee, "Locke on Executive Power and Liberal Constitutionalism": Canadian Journal of Political Science, vol. 38, n. ${ }^{\circ} 3$ (2005), pp. 719-774.

Weaver, David R., "Leadership, Locke and the Federalist": American Journal of Political Science, vol. 41, n. ${ }^{\circ} 2$ (1997), pp. 420-446. 
Wootton, David, “John Locke and Richard Ashcraft's Revolutionary Politics”: Political Studies, vol. 40, n. ${ }^{\circ} 1$ (1992), pp. 79-98.

Yolton, John W., "Locke on the Law of Nature": The Philosophical Review, vol. 67, n. ${ }^{\circ} 4$ (1958), pp. 477-498. 